\title{
Intraluminal and Mucosal Starch Digestion in Congenital Deficiency of Intestinal Sucrase and Isomaltase Activities
}

\author{
S. Auricchio ${ }^{[48]}$, F. Cracimarra, L. Moauro, F. Rey, J. Jos, and J. Rey \\ Gruppo di Ricerca in Gastroenterologia del Consiglio Nazionale delle Ricerche, Clinica Pediatrica II, Università di Napoli, Naples, Italy, \\ and Unité de Recherches de Génétique Médicale, Hôpital des Enfants Malades, Paris, France
}

\section{Extract}

Ten patients affected by congenital deficiency of intestinal sucrase and isomaltase activities were studied. The intraluminal $\alpha$-amylolysis of amylopectin was found to be normal in these patients. It is incomplete during the 1 st year of life, both in patients and in controls, as a consequence of the lower $\alpha$-amylase activity in this age group.

Maltotriose was well tolerated in two normal controls ages 32 and 3 months and in one 31-month-old patient: in these subjects an oral tolerance test with the trisaccharide was followed by a rapid increase of blood glucose $(46-58 \mathrm{mg} / 100 \mathrm{ml})$ and did not cause diarrhea. However, in a 6-month-old patient fermentative diarrhea and low increase of blood glucose $(24 \mathrm{mg} / 100 \mathrm{ml})$ followed oral load with maltotriose. In all patients, enzyme assays on intestinal biopsy specimens showed that the glucamylase activity of the heat-resistant maltase(s) was normal, while that of the sucrase-isomaltase complex was decreased.

These results suggest that starch malabsorption in congenital sucrose and isomaltose intolerance results from deficiency of the enzymatic activities of the sucrase-isomaltase complex involved in starch digestion.

\section{Speculation}

Malabsorption of starch can be expected to result from: (1) deficiency of pancreatic amylase; (2) congenital or acquired deficiency of the glucosidase activities of the brush border; (3) glucose malabsorption; (4) higher intestinal flow rate. The results in this study show that one particular form of starch malabsorption is a consequence of congenital deficiency of the activities of the sucrase-isomaltase complex involved in starch digestion. The methods used here should prove to be useful also in the investigation of other forms of starch malabsorption.

\section{Introduction}

Starch digestion results from the combined action of enzymes in the intestinal lumen and of enzymes of the brush border surface of the intestinal epithelial cell. In the intestinal lumen, salivary and pancreatic amylases split starch into a mixture of maltose, maltotriose, and branched dextrins $[4,8]$ ( $\alpha$-amylase limit products). At the brush border surface of the enterocyte, the fol- 
lowing compounds are hydrolyzed into glucose by the heat-resistant maltase(s) and by the sucrase-isomaltase complex [12, 31]: (1) the $\alpha$-amylase limit products of starch digestion $[2 \mathrm{I}, 22,28,31]$; (2) the intermediary products of the $\alpha$-amylolysis of starch, such as maltotetraose and higher linear and branched oligosaccharides $[1,29]$; and (3) starch and glycogen $[1,6,13,14$, 30, 32] (Table I).

It is well known that on ingestion of starch patients with congenital deficiency of intestinal sucrase and isomaltase activities get fermentative diarrhea of a considerably milder degree than upon ingestion of sucrose $[7,9,27,33]$. Actually, the intestinal mucosa of these patients was found to be deficient not only in sucrase and isomaltase $[2,10]$, but also in maltase [10], maltotriase [22], and glucamylase [15] activities.

This paper describes in vivo and in vitro studies on digestion of starch in children with congenital deficiency of sucrase and isomaltase activities and in normal controls. The intraluminal $\alpha$-amylolytic digestion of starch was studied by analyzing the carbohydrates which accumulate in the proximal jejunum after a test meal containing amylopectin. Some aspects of mucosal starch digestion were also investigated by performing maltotriose tolerance tests and by assaying the glucamylase activity in bioptic specimens of intestinal mucosa.

\section{Material and Methods}

Ten patients affected by congenital deficiency of intestinal sucrase and isomaltase activities [27] were investigated. At the time of the first investigation, $p a-$ tients 1 and 4 , ages 4 and 6 months, respectively, were kept on a starch- and sucrose-free diet; the only sugars fed to them were glucose and lactose. The remaining patients were also kept on a sucrose-free diet, but they received a small amount of starch. The control group was fed a diet containing sucrose and starch. In every case informed consent for the intubation was obtained from the parents.

Intubation studies using a single-lumen tube were carried out in five patients and in three controls after oral administration of a test meal containing amylopectin [37], casein [38], and oil. Details on the composition of the test meal were previously given [8]. The intestinal juice was continuously collected from the proximal $20-\mathrm{cm}$ segment of jejunum for 1 - to 3 -hr periods [8]. Collection was made directly into a vessel which was maintained in a freezing solution of Dry Ice and acetone. At the end of collection, the juice was rapidly homogenized at $+4^{\circ}$. Assay of pancreatic enzymes,
Table I. Intestinal glycosidase activities involved in starch digestion

\begin{tabular}{|c|c|}
\hline Enzymes & Substrates \\
\hline $\begin{array}{l}\text { Sucrase-isomaltase } \\
\text { complex (destroyed } \\
\left.\text { by heating at } 56^{\circ}\right)\end{array}$ & $\begin{array}{l}\text { Maltose }[31] \\
\text { Maltotriose }[22,28] \\
\text { Isomaliosz }[31] \\
\text { Low molecular weight branched } \\
\text { dextrins }[21] \\
\text { Low molecular weight fractions of } \\
\text { soluble starch (glucamylase ac- } \\
\text { tivity })[3,6]\end{array}$ \\
\hline $\begin{array}{l}\text { Heat-resistant malt- } \\
\text { ase (s) (resistant to } \\
\left.\text { heating at } 56^{\circ}\right)\end{array}$ & $\begin{array}{l}\text { Maltose [31] } \\
\text { Maltotriose [22, 28] } \\
\text { Isomaltose [31] } \\
\text { Low and high molecular weight } \\
\text { fractions of soluble starch; glyco- } \\
\text { gen (glucamylase activity) }[1,6 \text {, } \\
14,30,32]\end{array}$ \\
\hline
\end{tabular}

${ }^{1}$ Glucamylase enzymes are able to hydrolyze starch and glycogen directly in to glucose.

measurement of the average degree of polymerization (DP) of total carbohydrates, and fractionation of the carbohydrates on Sephadex G-50 [39] and on a charcoal-celite column $[40,41]$ were carried out according to methods previously described [8]. The only modifications concern the chromatography on charcoal: following deactivation with $\mathrm{HCl}$, charcoal was treated with a $2.5 \%$ solution of stearic acid in absolute ethanol; furthermore, elution of the sugars in the 1 to $4 \mathrm{DP}$ range was achieved by a water to $10 \%$ tertiary butanol gradient [18]; the column was subsequently washed with $20 \%$ tertiary butanol in water, in order to elute the remaining dextrins. These modifications improved recovery of branched dextrins from the column.

Oral tolerance tests were done in two patients and in two controls with $50 \mathrm{~g} / \mathrm{m}^{2}$ of amylopectin [37], maltose [38], and maltotriose given as $15 \%$ watery solution. Glucose was determined in capillary blood by the glucose-oxidase method [20] before and 10-180 min after ingestion of the test solution. Stools were collected during the 24-hr period preceding and the 72-hr period following oral administration of the test substance: in each stool sample, $\mathrm{pH}$ [9], lactic acid [33], glucose, and starch [5] were determined. Carbohydrates in stool were separated and detected by thin layer chromatography [34] after treatment of feces with acetone [17]. Maltotriose was prepared in our laboratory according to the procedure described in the appendix to this paper.

The disaccharidase activities were assayed according to Auricchio et al. [11]. The enzymatic activity hydrolyzing soluble starch directly into glucose (i.e., glucamyl- 
ase activity) was assayed: (1) as "total glucamylase," after tryptic inactivation of the $\alpha$-amylase; and (2) as "heat-resistant glucamylase" after heat inactivation of the $\alpha$-amylase and of the sucrase-isomaltase complex $[3,6,30]$.

For tryptic inactivation, a $2 \%, w / v$, homogenate in distilled water was added, volume by volume, to $0.2 \mathrm{M}$

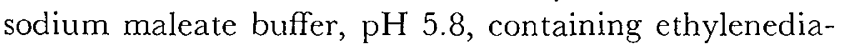
minetetraacetate (EDTA, $4 \mu$ moles $/ \mathrm{ml}$ ) and twice crystallized trypsin [42] ( $1 \mathrm{mg} / \mathrm{ml}$ ); the mixture was incubated at $37^{\circ}$ for $30 \mathrm{~min}$. For heat inactivation, the $2 \%$ homogenate was diluted with the same volume of $0.01 \mathrm{M}$ sodium phosphate buffer, $\mathrm{pH} 6.9$, containing $0.01 \mathrm{~m}$ EDTA and was heated at $56^{\circ}$ for $30 \mathrm{~min}$. After tryptic digestion or heat inactivation, glucamylase activity was determined as follows: $20 \mu$ l enzyme solution (0.02-0.1 unit enzyme activity per $\mathrm{ml} 0.1 \mathrm{~m}$ sodium maleate buffer, pH 5.8) were added to $20 \mu \mathrm{l} 2 \%$ soluble starch solution [43] in distilled water and were incubated at $37^{\circ}$ for $0 \mathrm{~min}, 30 \mathrm{~min}$, and $60 \mathrm{~min}$. The reaction was stopped by heating in a boiling water bath for $2 \mathrm{~min}$; then $280 \mu \mathrm{l}$ water and $40 \mu \mathrm{l}$ of both $10 \% \mathrm{ZnSO}_{4} \cdot 7 \mathrm{H}_{2} \mathrm{O}$ and $0.6 \mathrm{~N} \mathrm{NaOH}$ were added to the test tubes. After centrifugation, glucose was measured in the supernatant with the Tris-glucose-oxidase reagent [11]. One unit of glucamylase activity produces $1 \mu$ mole glucose/min.

Proteins were determined according to the method of Eggstein and Kreutz [16] using lyophilized albumin (bovine) [44] as standard.

\section{Intubation Studies}

\section{Results}

The levels of amylase, lipase, and trypsin in the intestinal juice of patients with congenital deficiency of su- crase and isomaltase activities were in the same range as controls (Table II). Furthermore, the intestinal content of glucose, oligosaccharides, and dextrins of three patients and one control, all older than 1 year, was not significantly different. The average degree of polymerization (DP) of total carbohydrates was 2.15 in the control and ranged between 2.42 and 2.53 in the patients. Dextrins with DP larger than 7 were $8 \%$ of total carbohydrates in the control and ranged between 11 and $15 \%$ in the patients. Most carbohydrates had DP smaller than 7; these were branched dextrins with DP between 5.11 and 5.85, as well as maltotriose, maltose, and glucose. No maltotetraose was found in this age group (Table III).

Two patients and two controls, ages from 6 to 13 months, displayed quite low levels of $\alpha$-amylase activity in intestinal juice (Table IV). In these subjects, the $\alpha$ amylolysis of amylopectin was less extensive, at least in the proximal part of jejunum. Indeed, dextrins with DP larger than 7 were present in larger amounts as compared to older subjects (24 and $26 \%$ of total carbohydrates in the controls and 27 and $40.4 \%$ in the patients) and the content of small branched dextrins was lower. Furthermore, maltotetraose was detected in one patient and in one control (Table IV).

\section{Oral Tolerance Test}

Maltotriose tolerance tests were performed in two controls ( 3 and 32 months old) and in two patients (6 and 31 months old). In the controls and in the 31 -monthold patient the administration of maltotriose was followed by an increase of blood glucose to $46-58 \mathrm{mg} / 100$ $\mathrm{ml}$ during the $1 \mathrm{st} \mathrm{hr}$. Similar results were obtained after

Table II. Pancreatic enzymes and average degree of polymerization of total carbohydrates (DP) in intestinal juice of patients with congenital sucrase-isomaltase deficiency and in normal controls, after a test meal containing amylopectin ${ }^{1}$

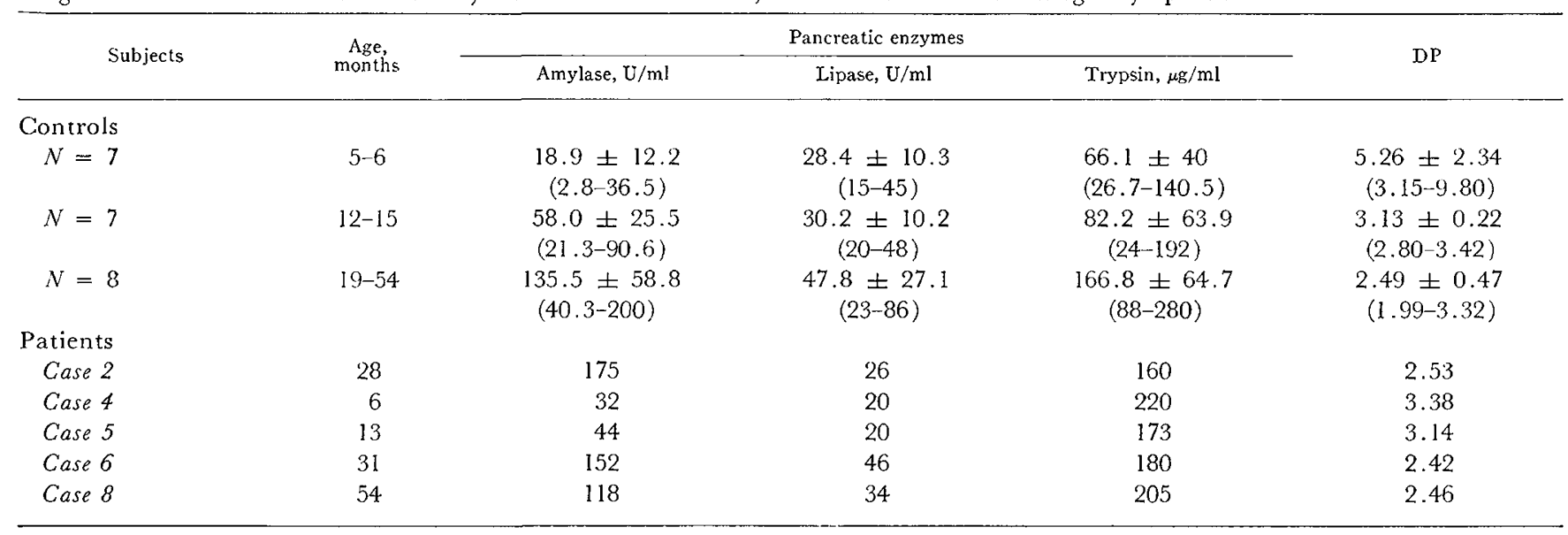

\footnotetext{
${ }^{1}$ Values are means $\pm \mathrm{SD}$. Ranges are reported in parentheses.
} 
Table III. Glucose, oligosaccharides, and dextrins of different degrees of polymerization (DP) present in intestinal juice of patients with congenital sucrase-isomaltase deficiency and in a normal control ${ }^{1}$

\begin{tabular}{|c|c|c|c|c|c|c|c|c|}
\hline & \multicolumn{2}{|c|}{ Patient 2 (28 months) } & \multicolumn{2}{|c|}{ Patient 6 (31 months) } & \multicolumn{2}{|c|}{ Palient 8 (54 months) } & \multicolumn{2}{|c|}{ Control (33 months) } \\
\hline & $\%^{2}$ & $\mathrm{DP}$ & $\%$ & $\mathrm{DP}$ & $\%$ & $\mathrm{DP}$ & $\%$ & $\mathrm{DP}$ \\
\hline Dextrins $\mathrm{DP}>7$ & 13.7 & 10.35 & 15.0 & 8.90 & 11.0 & 13.70 & 8.0 & 11.70 \\
\hline Branched dextrins & 23.3 & 5.85 & 27.3 & 5.69 & 27.0 & 5.54 & 25.5 & 5.11 \\
\hline Maltotetraose & 0 & & 0 & & 0 & & 0 & \\
\hline Maltotriose & 18.0 & 2.89 & 13.3 & 2.89 & 16.5 & 2.87 & 11.2 & 3.15 \\
\hline & Sephadex & Charcoal & Sephadex & Charcoal & Sephadex & Charcoal & Sephadex & Charcoal \\
\hline DP of carbohydrates put on column & 2.53 & 2.34 & 2.42 & 2.16 & 2.46 & 2.38 & 2.15 & 2.00 \\
\hline DP of recovered carbohydrates & 2.60 & 2.30 & 2.43 & 2.29 & 2.62 & 2.53 & 2.14 & 2.10 \\
\hline Recovery from column, $\%$ & 94.0 & 88.5 & 96.3 & 92.0 & 88.0 & 90.0 & 97.0 & 88.0 \\
\hline
\end{tabular}

1 The $\alpha$-amylase activity was $175,152,118$, and $190 \mathrm{U} / \mathrm{ml}$ intestinal juice in patients 2,6 , and 8 and in the control, respectively.

${ }^{2}$ Results are expressed as percentage of total carbohydrates recovered from the columns.

maltose and amylopectin tolerance tests (Figs. 1 and 2). Stools remained normal, with neutral $\mathrm{pH}$ and insignificant amounts of lactic acid and sugars.

In the 6-month-old patient, on the contrary, maltotriose ingestion was followed by an increase of blood glucose to only $24 \mathrm{mg} / 100 \mathrm{ml}$ (Fig. 2); liquid stools were passed showing a low $\mathrm{pH}(4.6)$, a high concentration of lactic acid, but no maltotriose or maltose. In contrast, maltose and amylopectin were well tolerated also in this patient, producing an increase of blood glucose to 41 and $32 \mathrm{mg} / 100 \mathrm{ml}$, respectively, and no symptom of fermentative diarrhea.

\section{Glucamylase Activity}

The glucamylase and the maltase activities of the heat-resistant maltase(s) were normal in the intestinal

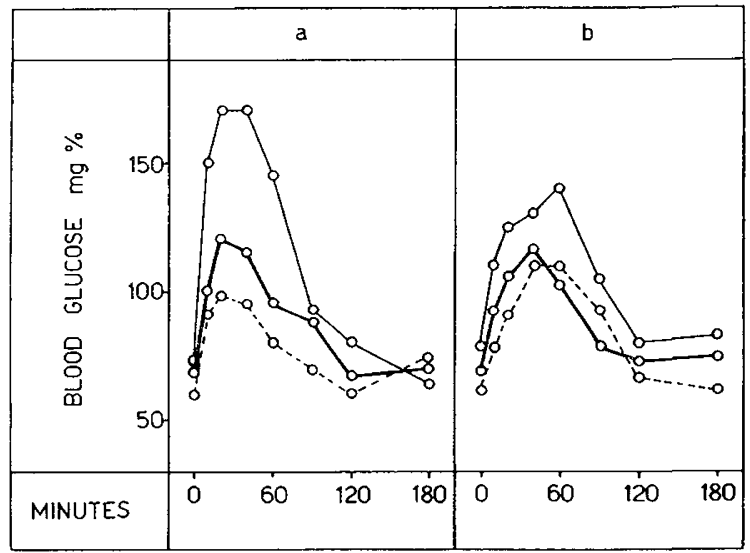

- MALTOTRIOSE — MALTOSE -...- AMYLOPECTIN

Fig. 1. Blood glucose curves in oral tolerance tests in two normal controls. a: Age: 3 months. b: Age: 32 months.

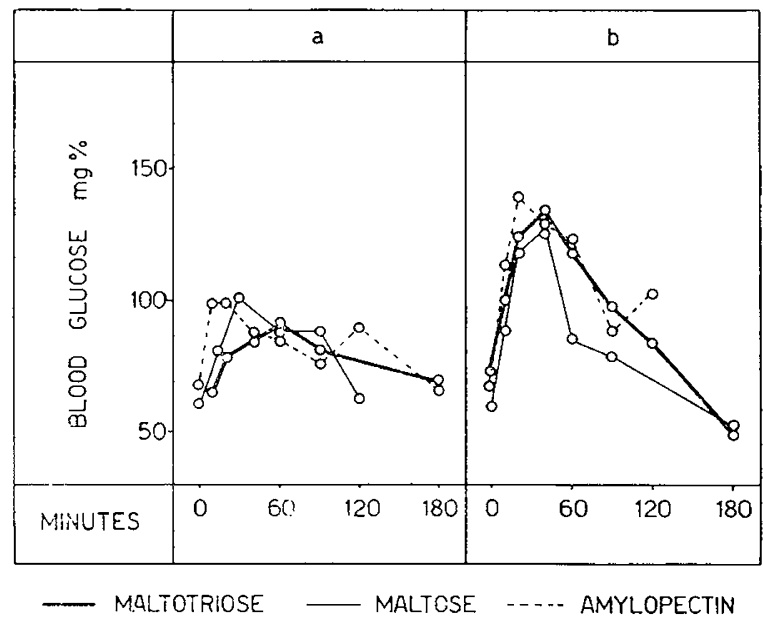

Fig. 2. Blood glucose curves in oral tolerance tests in two patients with congenital sucrase-isomaltase deficiency. $a$ : Case 4 , age: 6 months. $b$ : Case 6 , age: 31 months.

mucosa of patients. On the contrary, the heat-labile fraction of the total glucamylase activity, which is probably due to the sucrase-isomaltase complex, was clearly lower in patients than in controls $(P<0.001)$. As a consequence, a larger fraction of total glucamylase activity is resistant to heating in patients as compared to controls: in patients, the heat-resistant glucamylase activity ranges from 74 to $97.2 \%$ of total activity; in controls, it ranges from 45.3 to $62.5 \%(P<0.001)$ (Table V). Nevertheless, decrease of total glucamylase activity in patients was not evident. This is probably due to the large scatter of the values and to the large contribution of the heat-resistant maltase(s) to total glucamylase activity. 
Table IV...Glucose, oligosaccharides, and dextrins of different degrees of polymerization (DP) present in intestinal juice of patients with congenital sucrase-isomaltase deficiency and in normal controls ${ }^{1}$

\begin{tabular}{|c|c|c|c|c|c|c|c|c|}
\hline & \multicolumn{2}{|c|}{ Patient 4 (6 months) } & \multicolumn{2}{|c|}{ Patient 5 (13 months) } & \multicolumn{2}{|c|}{ Control 1 (8 months) } & \multicolumn{2}{|c|}{ Control 2 (12 months) } \\
\hline & $\%^{2}$ & $\mathrm{DP}$ & $\%$ & $\mathrm{DP}$ & $\%$ & DP & $\%$ & $\mathrm{DP}$ \\
\hline Dextrins DP $>7$ & 40.4 & 15.30 & 27.0 & 15.40 & 24.0 & 13.50 & 26.0 & 15.10 \\
\hline Branched dextrins & 9.8 & 5.01 & 16.1 & 5.33 & 8.1 & 6.20 & 25.0 & 5.30 \\
\hline Maltotetraose & 6.4 & 4.10 & 0 & & 3.5 & 4.25 & 0 & \\
\hline Maltotriose & 16.6 & 3.10 & 18.6 & 2.87 & 21.1 & 3.00 & 16.8 & 3.10 \\
\hline Glucose & Sephadex & Charcoal & Sephadex & Charcoal & Sephadex & Charcoal & Sephadex & Charcoa \\
\hline DP of carbohydrates put on column & 3.38 & 2.30 & 3.14 & 2.50 & 3.04 & 2.40 & 2.93 & 2.32 \\
\hline DP of recovered carbohydrates & 3.50 & 2.40 & 3.23 & 2.47 & 3.00 & 2.35 & 2.97 & 2.55 \\
\hline Recovery from column, $\%$ & 95.1 & 88.8 & 91.0 & 88.3 & 96.5 & 95.0 & 97.0 & 81.0 \\
\hline
\end{tabular}

1 The $\alpha$-amylase activity was 32,44,75, and $80 \mathrm{U} / \mathrm{ml}$ intestinal juice in patients 4 and 5 and in controls 1 and 2, respectively.

${ }^{2}$ Results are expressed as percentage of total carbohydrates recovered from the columns.

Table $V$. Glycosidase activities of intestinal biopsy specimens from patients with congenital sucrase-isomaltase deficiency and from control subjects ${ }^{1}$

\begin{tabular}{|c|c|c|c|c|c|c|c|c|c|c|}
\hline \multirow{3}{*}{ Subjects } & \multirow{3}{*}{$\begin{array}{c}\text { Age } \\
\text { (years/ } \\
\text { months) }\end{array}$} & \multirow{3}{*}{$\begin{array}{l}\text { Biopsy } \\
\text { site }\end{array}$} & \multicolumn{8}{|c|}{ Enzymic activities } \\
\hline & & & \multicolumn{6}{|c|}{ units/g protein } & \multirow{2}{*}{\multicolumn{2}{|c|}{$\begin{array}{l}\text { Heat-resistant, } \\
\% \text { of total activity }\end{array}$}} \\
\hline & & & Sucrase & Isom altase & Maltase & $\begin{array}{l}\text { Total } \\
\text { gluca- } \\
\text { mylase }\end{array}$ & \multicolumn{2}{|c|}{ Heat-resistant } & & \\
\hline \multicolumn{11}{|l|}{ Controls } \\
\hline 1 & $0 / 7$ & D & 53.5 & & 151.7 & 24.3 & 28.2 & 11.0 & 18.6 & 45.3 \\
\hline 2 & $1 / 0$ & J & 57.9 & 60.3 & 189.0 & 15.8 & 20.3 & 8.5 & 10.7 & 53.8 \\
\hline 5 & $4 / 0$ & $\mathrm{D}$ & 54.0 & 52.6 & 152.0 & 28.1 & 23.3 & 14.0 & 15.3 & 49.8 \\
\hline 6 & $5 / 0$ & $\mathrm{D}$ & 52.8 & & 163.7 & 24.6 & 24.6 & 12.8 & 15.0 & 52.0 \\
\hline 7 & $6 / 0$ & $\mathrm{D}$ & 46.1 & 56.1 & 163.4 & 23.9 & 20.1 & 12.3 & 12.3 & 51.5 \\
\hline 8 & $7 / 0$ & $J$ & 121.8 & & 376.6 & 48.5 & 39.6 & 29.5 & 10.5 & 60.8 \\
\hline \multicolumn{11}{|l|}{ Patients } \\
\hline 1 & $0 / 4$ & D-J & 1.7 & 1.5 & 33.0 & 24.3 & 27.4 & 20.4 & 83.0 & 83.9 \\
\hline 6 & $5 / 3$ & $J$ & 0 & 3.5 & 100.3 & 51.8 & 71.8 & 46.6 & 71.6 & 90.0 \\
\hline 7 & $6 / 3$ & $D$ & 0 & 1.1 & 24.5 & 14.5 & 20.9 & 12.3 & 85.3 & 84.8 \\
\hline 8 & $6 / 6$ & $\mathrm{D}$ & 2.5 & 3.0 & 38.1 & 16.1 & 23.6 & 13.6 & 61.9 & 84.5 \\
\hline 9 & $6 / 9$ & $\mathrm{D}$ & 0 & 7.4 & 31.9 & 18.2 & 16.4 & 13.7 & 51.4 & 75.3 \\
\hline 10 & $10 / 1$ & $\mathrm{D}-\mathrm{J}$ & 0 & 0.3 & 21.0 & 10.7 & 19.1 & 10.4 & 91.0 & 97.2 \\
\hline
\end{tabular}

All samples were obtained from the last portion of duodenum (D) or from the first part of jejunum, about $10 \mathrm{~cm}$ from the ligament of Treitz (J).

\section{Discussion}

\section{Intraluminal Hydrolysis of Starch}

When amylopectin is given to subjects older than 1 year, maltose, maltotriose, and branched dextrins (with DP smaller and larger than 7) are found in the lumen of proximal jejunum, without any significant difference between patients and controls. All the above carbohydrates are not further hydrolyzed in vivo by the $\alpha$-amylase $[19,23-25,35]$.

When amylopectin is given to subjects younger than 1 year, the intraluminal digestion of the polysaccharide is 
incomplete. Indeed, one finds that the intestinal juice contains large amounts of high molecular weight branched dextrins, in some cases together with small amounts of maltotetraose. This accumulation appears to be a consequence of the lower levels of $\alpha$-amylase activity in this age group. Similar results were obtained in normal children and infants in a previous study [8] with the difference, however, that a higher concentration of branched dextrins is found in the present series of subjects; this difference probably derives from the modification of the charcoal chromatography technique introduced in this study.

The intubation studies thus show that the intraluminal $\alpha$-amylolysis of amylopectin is normal in patients with congenital deficiency of sucrase and isomaltase activity.

\section{Mucosal Hydrolysis of Starch}

It was known that patients with sucrose and isomaltose intolerance are deficient in some of the glucosidase activities of the enterocyte brush border which are involved in starch digestion. These deficient activities are the maltase, the isomaltase, and the maltotriase activities of the sucrase-isomaltase complex $[2,10,22]$.

It has now been found that peroral administration of maltotriose causes fermentative diarrhea in a 6 -month-old patient. This finding suggests that maltotriose intolerance is one of the factors involved in starch malabsorption in patients with sucrose and isomaltose intolerance.

A further finding in this paper is that the glucamylase activity of the sucrase-isomaltase complex is severely reduced in these patients. However, glucamylase as well as maltase activities [10] of the heat-resistant maltase(s) were found to be normal in the same patients. Thus, the claim that all intestinal maltases are affected in these patients, which is based on the finding of low levels of glucamylase activity in intestinal biopsies using glycogen as substrate [15], is not supported by present findings.

\section{Conclusion}

Based on previous discussion, we conclude that starch malabsorption in congenital sucrose and isomaltose intolerance is a consequence of deficient enzymatic activities of the sucrase-isomaltase complex, which are involved in starch digestion, that is, the maltase, oligo1,4- and oligo-1,6-glucosidase as well as the glucamylase activities. This enzymatic defect impairs the mucosal ability to digest the end products of the $\alpha$-amylolysis of starch such as maltose, maltotriose, and low and high molecular weight branched dextrins.

In patients during the first few months of life the situation is made worse by the physiologically incomplete intraluminal hydrolysis of the polysaccharide. Indeed, during this age period it is the intestinal mucosa which is responsible not only for digestion of the final products of the intraluminal $\alpha$-amylolysis of starch ( $\alpha$-amylase limit products) but also for providing the alternative glucamylolytic pathway for digestion of the intermediary products of the same $\alpha$-amylolysis.

\section{Summary}

Analysis of the carbohydrates in the intestinal juice after a test meal containing amylopectin was carried out in five patients with sucrose and isomaltose intolerance and in three normal control subjects. The results indicate that the intraluminal $\alpha$-amylolysis of starch in the proximal jejunum is normal in these patients. After the first year of life, the intestinal juice contains glucose, maltose, maltotriose, and low and high molecular weight branched dextrins. On the contrary, intraluminal digestion of the polysaccharide is incomplete both in patients and in control subjects younger than 12 months of age as a consequence of the physiologically low level of $\alpha$-amylase activity. The maltotriose oral tolerance test was normal in a 31 -month-old patient, whereas it caused fermentative diarrhea and only a small increase of blood glucose in a 6-month-old patient. The glucamylase activity of the heat-resistant maltase(s) is normal, whereas that of the sucrase-isomaltase complex is reduced. These results demonstrate that starch malabsorption in congenital sucrose and isomaltose intolerance results from deficiency of some of the glucosidase activities of the brush border involved in starch digestion.

\section{Appendix}

\section{Preparation of Maltotriose}

Amylose, $1 \%$ [45], in $0.001 \mathrm{~m}$ sodium potassium phosphate buffer, $\mathrm{pH}$ 6.9, was boiled for $30 \mathrm{~min}$ and then incubated at $25^{\circ}$ for $16 \mathrm{hr}$ with filtered human saliva; there were 6 units $\alpha$-amylase activity per ml incubation mixture. After inactivation of salivary $\alpha$-amylase in a boiling water bath for $15 \mathrm{~min}$, the amylose hydrolysate was suction-filtered in a Büchner funnel, through a double sheet of Whatman paper no. 1. The filtrate contains large amounts of maltose and maltotriose and small amounts of glucose and maltotetraose. A mixture of $300 \mathrm{~g}$ charcoal [38] and $150 \mathrm{~g}$ celite [37], prepared according to Whistler and BeMiller [36], was packed in a large Büchner funnel (26 cm diameter) on a double sheet of Whatman paper no. 1. Then 10-12 liters hy- 
drolysate were filtered with moderate suction, in about $1 \mathrm{hr}$, in order to make the oligosaccharides absorb on the charcoal (dimensions of absorbent were $24.5 \times 4$ $\mathrm{cm}$ ). Five liters water were subsequently allowed to flow through, in order to remove salts, glucose, and part of the maltose. A water to $15 \%$ ethanol gradient was then applied: the reservoir of ethanol and a 6-liter mixing chamber containing 3 liters water were placed 60 and $20 \mathrm{~cm}$ above the Büchner funnel, respectively. The flow rate was approximately 2 liters/hr. Fractions of about 1 liter each were collected under reduced pressure; when maltotriose appeared in the eluate, the gradient was stopped and the maltotriose was eluted with approximately 10 liters ethanol solution from the mixing chamber.

Fractions containing maltotriose were mixed together and filtered on $47-\mathrm{mm}$ diameter filters [46] (pore size $0.8 \mu$; pressure $100 \mathrm{psi}$ ) in order to eliminate charcoal and celite particles. The sugar was obtained from the filtrate according to Pazur [26]. Maltotriose, $7.3 \mathrm{~g}$, with an impurity of $9 \%$ of maltose and trace amounts of maltotetraose were obtained from $100 \mathrm{~g}$ amylose.

\section{References and Notes}

1. Alpers, D. H., and Solin, M.: The characterization of rat intestinal amylase. Gastroenterology, 58: 833 (1970).

2. Anderson, C. M., Messer, M., Townley, R. R. W., and Freeman, M.: Intestinal sucrase and isomaltase deficiency in two siblings. Pediatrics, 31: 1003 (1963).

3. Auricahio, S., and Ciccimarra, F.: Glucamylolytic digestion of starch in human intestinal mucosa. 7th Internat. Congr. Clin. Chem., Geneva/Evian, 1969, vol. 4: Digestion and Intestinal Absorption, p. 45. (Karger, Basel, 1970).

4. Auricchio, S., Ciccimarra, F., Della Pietra, D., and Vegnente, A.: Intestinal hydrolysis of starch. Mod. Probl. Paediat., 11: 22 (1968).

5. Auricchio, S., Ciccimarra, F., Rubino, A., and Prader, A.: Studies on intestinal digestion of starch in man. III. The absorption coefficient of starch in infants and children. Enzymol. Biol. Clin., 9: 321 (1968).

6. Aurigchio, S., Ciccimarra, F., Starace, E., Vegnente, A., Giliberti, P., and Provenzale, L.: Studies on intestinal digestion of starch in man. IV. Glucamylase activity of human intestinal mucosa. Rend. R. Gastroenterol., 3: 1 (1971).

7. Auricchio, S., Dahlovist, A., Mürset, G., and Prader, A.: Isomaltose intolerance causing decreased ability to utilize dietary starch. J. Pediat., 62: 165 (1963).

8. Auricchio, S., Della Pietra, D., and Vegnente, A.: Studies on intestinal digestion of starch in man. II. Intestinal hydrolysis of amylopectin in infants and children. Pediatrics, 39: 853 (1967).

9. Auricchio, S., Prader, A., Mürset, G., and Witt, G.: Saccharoseintoleranz. Durchfall infolge hereditären Mangels an intestinalen Saccharaseaktivität. Helv. Paediat. Acta, 16: 483 (1961).
10. Auricchio, S., Rubino, A., Prader, A., Rey, J., Jos, J., FrÉzAL, J., AND Davidson, M.: Intestinal glycosidase activities in congenital malabsorption of disaccharides. J. Pediat., 66: 555 (1965).

11. Auricchio, S., Rubino, A., Tosi, R., Semenza, G., Landoxt, M., Kistler, H., and Prader, A.: Disaccharidase activities in human intestinal mucosa. Enzymol. Biol. Clin., 3: 193 (1963).

12. Auricihio, S., Semenza, G., and Rubino, A.: Multiplicity of human intestinal disaccharidases. II. Characterization of the individual maltases. Biochim. Biophys. Acta, 96: 498 (1965).

13. Dahlevist, A., and Thomson, D. L.: Separation and characterization of two rat intestinal amylases. Biochem. J., 89: 272 (1963).

14. EgGermont, E.: The hydrolysis of the naturally occurring $\alpha$-glucosides by the human intestinal mucosa. Eur. J. Biochem., 9: 483 (1969).

15. Eggermont, E., and Hers, H. G.: The sedimentation properties of the intestinal $\alpha$-glucosidases of normal human subjects and of patients with sucrose intolerance. Eur. J. Biochem., 9: 488 (1969)

16. EgGstein, M., ANd Kreutz, F. H.: Vergleichende Untersuchungen zur quantitativen Eiweissbestimmung in Liquor und eiweissarmen Lösungen. Klin. Wochenschr., 33: 879 (1955).

17. Ford, J. D., and Haworth, J. C.: The fecal excretion of sugars in children. J. Pediat., 63: 988 (1963).

18. French, D., Robyt, J. F., Weintraub, M., and Knock, P.: Separation of maltodextrins by charcoal chromatography. J. Chromatogr., 24: 68 (1966).

19. Heller, J., And Schramm, M.: $\alpha$-Amylase limit dextrins of high molecular weight obtained from glycogen. Biochim. Biophys. Acta, 81: 96 (1964).

20. Hugget, A., ANd Nrxon, D. A.: Use of glucose-oxidase, peroxidase and 0 -dianisidine in determination of blood and urinary glucose. Lancet, ii: 368 (1957).

21. Larner, J., AND MCNickle, C. M.: Gastrointestinal digestion of starch. I. The action of oligo-1,6-glucosidase on branched saccharides. J. Biol. Chem., 215: 723 (1955).

22. Messer, M., AND KeRRy, K. R. : Intestinal digestion of maltotriose in man. Biochim. Biophys. Acta, 132: 432 (1967).

23. Nordin, P.: Action pattern of salivary amylase. Thesis, Iowa State College, Ames, 1953.

24. Nordin, P., AND FRENCH, D.: I-Phenyl-flavazole derivatives of starch dextrins. J. Amer. Chem. Soc., 80: 1445 (1958).

25. PAzUR, J. H.: The hydrolysis of amylotriose and amylotetraose by salivary amylase. J. Biol. Chem., 205: 75 (1953).

26. PAzUr, J. H.: Digestion of amylose with salivary amylase. In: Methods in Carbohydrate Chemistry, Vol. I, p. 337. (Academic Press, New York, 1962).

27. REY, J. In preparation.

28. Ruttloff, H., Friese, R., ANd Täufel, K.: Einwirkung von Darmfermenten auf Maltotriose. Hoppe-Seyler's Z. Physiol. Chem., 337: 137 (1964).

29. Ruttloff, H., Friese, R., and Täufel, K.: Die Bedeutung glucosidatischer enzyme bei der Zerlegung von Maltooligosacchariden und Stärke. Hoppe-Seyler's Z. Physiol. Chem., 348: 705 (1967).

30. Rutrloff, H., Friese, R., ANd TäUfel, K.: Zur Bestimmung der intestinalen $\gamma$-Amylase. Die Nahrung, 11: 205 (1967).

31. Semenza, G., Aurrcahio, S., and Rubino, A.: Multiplicity of human intestinal disaccharidases. I. Chromatographic separa- 
tion of maltases and of two lactases. Biochim. Biophys. Acta, 96: 487 (1965).

32. Thomson, D. L.: Separation and characterization of human intestinal mucosal amylases. Gastroenterology, 48: 854 (1965).

33. Weijers, H. A., Kamer, J. H. van de, Dicke, W. K., and IJSSELING, J.: Diarrhoea caused by deficiency of sugar splitting enzymes. Acta Pacdiat., 50: 55 (1961).

34. Weill, C. E., AND Hanke, P.: Thin-layer chromatography of malto-oligosaccharides. Anal. Chem., 34: 1736 (1962).

35. Whelan, W. J.: The action patterns of $\alpha$-amylases. Die Stärke, 12: 358 (1960).

36. Whistler, R. L., and BeMilller, J. N.: Carbon column chromatography. In: Methods in Carbohydrate Chemistry, Vol. I, p. 42. (Academic Press, New York, 1962).

37. Amylopectin (powder mol wt over 1,000,000) and Celite 535, Koch-Light Laboratory, Colnbrook, Bucks, England.

38. Casein, light white-soluble; maltose monohydrate; and activated charcoal powder for decolorizing purposes were obtained from British Drug Houses, Poole, England.
39. Pharmacia, Uppsala, Sweden.

40. Darco G-60 activated carbon, Fisher Scientific Company, Fair Lawn, N. J.

41. Celite 560, Johns-Manville International Company, Manville, N. J.

42. Mann Research Laboratory, New York, N. Y.

43. Soluble starch (according to Zulkowsky), E. Merck AG, Darmstadt, Germany.

44. Sigma Chemical Company, St. Louis, Mo.

45. Avebe, G. A., Veendam, Holland.

46. Millipore Corporation, Bedford, Mass.

47. The authors are grateful to Dr. K. G. de Noord (Avebe G. A. Veendam, Holland) and to Prof. R. Weidenhagen (Neuoffstein, Pfalz, Germany) for generous gift of amylose and isomaltose, respectively.

48. Requests for reprints should be addressed to: Professor SALvatore Auricahio, Department of Pediatrics II, University of Naples, S. Andrea delle Dame 4, 80138 Naples, Italy.

49. Accepted for publication July 18, 1972. 